\title{
Effects of low-level laser therapy on performance, inflammatory markers, and muscle damage in young water polo athletes: a double-blind, randomized, placebo-controlled study
}

\author{
Alessandro Moura Zagatto ${ }^{1}$ - Solange de Paula Ramos $^{2} \cdot$ Fábio Yuzo Nakamura ${ }^{2}$. \\ Fábio Santos de Lira ${ }^{3}$ - Rodrigo Álvaro Brandão Lopes-Martins ${ }^{4}$. \\ Rodrigo Leal de Paiva Carvalho ${ }^{5}$
}

Received: 5 February 2015 / Accepted: 14 January 2016/Published online: 12 February 2016

(C) Springer-Verlag London 2016

\begin{abstract}
This study aimed to evaluate the effects of 5 days of 810-nm low-level laser therapy (LLLT) intervention on inflammatory and muscle damage markers and performance in young water polo players. Twenty young male water polo players participated in the study, which was designed as a randomized, double-blinded, placebo-controlled trial. Active LLLT or an identical placebo LLLT were delivered to eight points on the adductor muscle region immediately after each training day. Performance was measured by a 200-m maximal swimming (P200) and a 30-s crossbar jump test (30CJ) which was performed every day before training, and blood samples were drawn pre and post the final LLLT intervention to measure interleukins (IL) and muscle damage markers. There was no significant change in the P200 exercise in the LLLT group compared with the placebo group but there was a moderate improvement in the $30 \mathrm{CJ}(8.7 \pm 2.6 \%)$. IL- $1 \beta$ and tumor necrosis factor-alpha presented increased $(P<0.016)$
\end{abstract}

Alessandro Moura Zagatto

azagatto@yahoo.com.br

1 Faculty of Sciences, Department of Physical Education, UNESP Univ Estadual Paulista, Av. Eng. Luiz Edmundo Carrijo Coube, 14-01, Vargem Limpa, CEP 17033-360 Bauru, São Paulo, Brazil

2 State University of Londrina, Londrina, Paraná, Brazil

3 Department of Physical Education, Faculty of Science and Technology, UNESP - Univ Estadual Paulista, Presidente Prudente, São Paulo, Brazil

4 Laboratory of Photobiomodulation and Modeling of Biological Phenomena, Universidade de Mogi das Cruzes (UMC), Mogi das Cruzes, São Paulo, Brazil

5 Research Laboratory in Physiotherapy, Sacred Heart University, Bauru, São Paulo, Brazil concentration within group $48 \mathrm{~h}$ after the last LLLT intervention compared to pre, 0 , and $24 \mathrm{~h}$, but did not differ between groups. IL-10 increased over time in the placebo group and reached a moderate effect compared to the LLLT group. The creatine kinase decreased significantly $(P=0.049)$ over the time within the LLLT treatment group, but there was no significant change in lactate dehydrogenase $(P=0.150)$. In conclusion, LLLT resulted in a non-significant, but small to moderate effect on inflammatory and muscle damage markers and a moderate effect on performance in water polo players. In addition, the lack of positive results could be due to the small area covered by irradiation and this should be considered in future studies.

Keywords Cytokines $\cdot$ Laser $\cdot$ Muscle injuries $\cdot$ Water polo

\section{Introduction}

In recent years, both the beneficial and harmful effects of exercise have been widely investigated [1-5]. In high-level competitive sports, athletes are required to undertake heavy training loads using different and sometimes concurrent methods (e.g., aerobic and strength training) to elicit physiological adaptations and improve performance [4]. The adoption of concurrent training strategies is a special feature of many teams in different sports modalities [6].

The training schedule of high-level athletes is generally considered a strong systemic stressor agent. A number of studies have investigated the relationship between exercise training and stress biomarkers, including muscle damage and inflammation [5, 7-9] in both acute and chronic responses to exercise $[7,8]$. 
After a period of single or multiple exposures to highintensity exercise, increased circulating levels of soluble muscle damage biomarkers such as lactate dehydrogenase and creatine kinase (in addition to inflammatory markers such as pro-inflammatory cytokines and C-reactive protein) are evident $[9,10]$. This is mainly observed in response to eccentric exercise [11-13]. Eccentric exercise or repeated high loads may damage muscle fibers (highlighted by increased blood creatine kinase and lactate dehydrogenase levels), impairing muscle function, and prompting an inflammatory reaction [1, $2,10]$. Therefore, without sufficient recovery time and reduction in training loads, signs and symptoms of overreaching/ overtraining may appear [2], making the athletes more susceptible to decreases in performance and increases in musculoskeletal injuries [14].

In real exercise situations, the most common methods used to speed up post-exercise recovery are active recovery [15] and cold water immersion [14]. More recently, low-level laser therapy (LLLT) has been used in the treatment of skeletal muscle injuries, to improve tissue repair [16], reduce inflammatory processes $[17,18]$, and delay the development of muscle fatigue [18, 19]. According to Leal Junior et al. [20], cold immersion was not effective in improving recovery from muscle damage after intensive exercises in high-level athletes. The authors clearly demonstrate that light therapy [i.e., lightemitting diode (LED) therapy] was significantly more effective for accelerating muscle recovery.

Antonialli et al. [21] demonstrated that early exposure to LLLT was quite effective in reducing delayed onset muscle soreness and creatine kinase activity, increasing the pain threshold, and maximal voluntary contraction with effective effects at doses of $30 \mathrm{~J}$. In addition, photobiomodulation therapy (i.e., laser and/or LED) seems to be effective in reducing muscle damage, delaying skeletal muscle fatigue [16, 18, 22-24], and possibly, improving performance due to greater adenosine triphosphate synthesis through the mitochondrial pathway [25].

Water polo is characterized by intermittent high-intensity activities (i.e., approximately $44 \%$ of the distance covered during the game is performed at velocities $>1.4 \mathrm{~m} \mathrm{~s}^{-1}$ ) [26], eliciting significant participation of the anaerobic metabolism (blood lactate $\sim 7.7 \pm 1.0 \mathrm{mmol} \mathrm{L}^{-1}$ ) [26]. In consequence, game simulations and training drills are often performed using repeated high-intensity efforts [26]. Due to these highintensity efforts and the consequent fatigue, the physical performance of water polo players during the final quarter of the game is often decreased, as manifested by reduced distance covered $(\sim 7 \%)[26]$ and deterioration in skill proficiency and technical performance (i.e., a decrement of about $43 \%$ ) [27]. Due to the highly demanding activities inherent in water polo and significant muscle fatigue produced by this sport modality, we hypothesized that LLLT may play a role in muscle recovery and fatigue, accelerating the process of recovery from training and helping coaches and physical trainers to manage the training loads while avoiding excessive fatigue and/or overtraining.

In addition, during a defensive or offensive action, when the players are in a quasi-vertical floating position (e.g., male water polo players spend from 55 to $67 \%$ of a game in various options of the quasi-vertical floating position) [28], the players mainly perform the eggbeater kick, instead of the breaststroke "whip kick," which consists of the right leg rotating counterclockwise while the left rotates clockwise in a kick unique to water polo. The adductor longus plays the major role in the adduction motion, principally during the power phase of the eggbeater kick [29]. Therefore, a high proportion of fatigue during water polo is associated with fatigue in the lower limbs.

The purpose of the present study was to evaluate the effects of low-level laser irradiation on inflammatory and muscle damage markers and also on 200-m performance and a water polo anaerobic-specific test in young water polo players after 5 days of high-intensity training. Our scientific hypothesis was that LLLT would significantly reduce the production of inflammatory mediators and muscle damage signs, enhancing or maintaining performance compared to the control (non-irradiated-placebo) conditions.

\section{Methods}

\section{Subjects}

Twenty young male polo players participated in the study (age $15.4 \pm 1.2$ years, body mass $68.3 \pm 10.5 \mathrm{~kg}$, height 173.9 $\pm 5.9 \mathrm{~cm}$, and body mass index $22.5 \pm 2.6 \mathrm{~kg} / \mathrm{m}^{2}$ ). The players had at least 2 years of training and competition experience.

\section{Inclusion and exclusion criteria}

Only athletes who did not present any kind of tendon, joint, or skeletal muscle lesions during the previous 12 months were included in the sample. The athletes were also prohibited from taking any kind of analgesic or anti-inflammatory drugs.

All procedures were approved by the University's Institutional Review Board for Human Subjects (Human Research Ethics Committee; Process number 900.455/14) and conducted in accordance with the Declaration of Helsinki. The athletes and their parents were informed about the experimental procedures and risks, and both provided a written informed consent form authorizing the athletes' participation in the study.

\section{Training routine}

The training routine consisted of 6 days per week with sessions lasting $4 \mathrm{~h}$ per day $(2 \mathrm{~h}$ of swimming training and $2 \mathrm{~h}$ of water polo training, except Saturday_match simulation). 


\section{Experimental design}

A randomized, double-blind, placebo-controlled, parallelgroup study was conducted. The randomization was performed using Excel (Microsoft ${ }^{\circledR}$ Corporation, Redmond, Washington, USA), considering the matching players by position, individual best time in the $200-\mathrm{m}$ swimming and anaerobic threshold. This randomization procedure permitted formation of groups with similar performance (i.e., both groups with players with low, medium, and high performances) and water polo positions.

Initially, the subjects performed an incremental test for anaerobic threshold determination and body composition analysis using a dual energy $\mathrm{x}$-ray absorptiometry scanner (DEXA) (Hologic Discovery, Hologic, Inc., Waltham, MA, USA), which were used to characterize the sample.

In addition to the incremental test and DEXA (Hologic Discovery, Hologic, Inc., Waltham, MA, USA), the athletes were submitted to a maximal 200-m effort before and after the intervention period (i.e., $48 \mathrm{~h}$ after the last LLLT intervention) and a 30 -s crossbar jump test (30CJ), which was also performed every day during the 5-day intervention to monitor specific performance. Blood samples were collected at rest conditions, immediately before the intervention treatment (baseline - Tuesday) and 0, 24, and $48 \mathrm{~h}$ after the final day of the LLLT intervention. A schematic summary of the study design is presented in Fig. 1.

\section{Low-level laser therapy}

For low-level laser therapy (LLLT), the athletes were randomly allocated into two groups according to their water polo game position (i.e., goal keepers, center forwards, center defenders, and field players) and swimming performance (i.e., 200-m performance and anaerobic threshold); the laser and placebo groups. The LLLT was performed in a double-blinded design.
During the experimental week, the athletes undertook daily training sessions in the afternoon. Application of the laser or placebo took place 5-40 min immediately after each daily training session, in a counterbalanced order. Due to the prevalence of the active eggbeater kick during water polo (i.e., specific water polo kick) and the fact that adductor muscle strains are a common injury in sports that involve sudden changes of direction such as water polo, the probe was applied to eight points of the adductor magnus and adductor longus muscles. Laser/placebo irradiations were performed in two parallel lines (interspaced by $\sim 2 \mathrm{~cm}$ ) of four spots interspaced by $\sim 2 \mathrm{~cm}$, with the first point located around $4 \mathrm{~cm}$ from the groin, focusing on performing laser irradiation in the muscle belly. This was based on findings that the area of pain and tenderness is usually located either in the belly of the adductor longus, the proximal musculotendinous junction or the tendon, near its origin on the inferior pubic ramus [30]. Considering the spot size area (i.e., $0.028 \mathrm{~cm}^{2}$ ) resulting in a small area of tissue covered by irradiation, eight spots per leg were irradiated to attain a wide muscular area. A representative picture of the points where the probe was applied is presented in Fig. 2. The LLLT was applied by means of an infrared laser unit (DMC ${ }^{\circledR}$; Sao Carlos, Sao Paulo, Brazil). The optical output of the laser unit was measured before, halfway through, and after the study to check calibration. The optical power was calibrated using a Newport multifunction optical meter model $1835{ }^{\circ} \mathrm{C}$ (Newport, Irvine, CA, USA). The stability of the laser during the laser irradiation was measured, collecting light with a partial reflect (4\%). The optical power output of the laser unit was measured before, halfway through, and after the experiment. All measurements of state parameters were performed at laser aperture and the manufacturer supplied the laser beam information. The details of LLLT irradiation are shown in Table 1. In addition, the wavelength of $810 \mathrm{~nm}$ was chosen as it can transmit light energy from 2 to $4 \mathrm{~cm}$ beyond the skin, therefore reaching soft tissue such as muscles, ligaments, and tendons [18].
Fig 1 A schematic summary of the study design. Baseline measures, application of LLLT after each training session and blood samples drawn immediately $(0 \mathrm{~h})$ and 24 and $48 \mathrm{~h}$ after the final LLLT intervention
Low-Level Laser Therapy Intervention applied after each training session

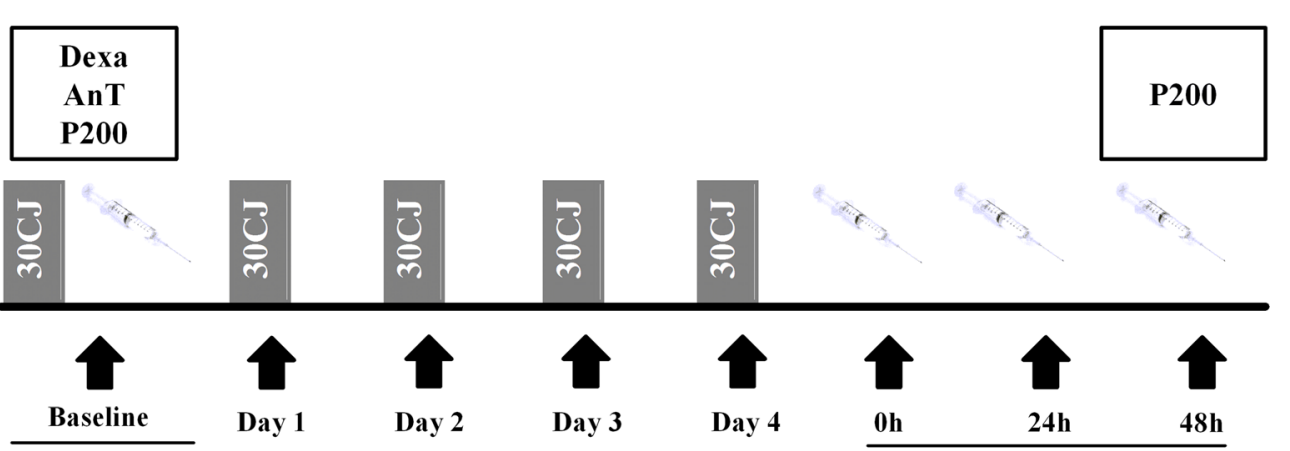

Pre LLTI

Post LLTI 


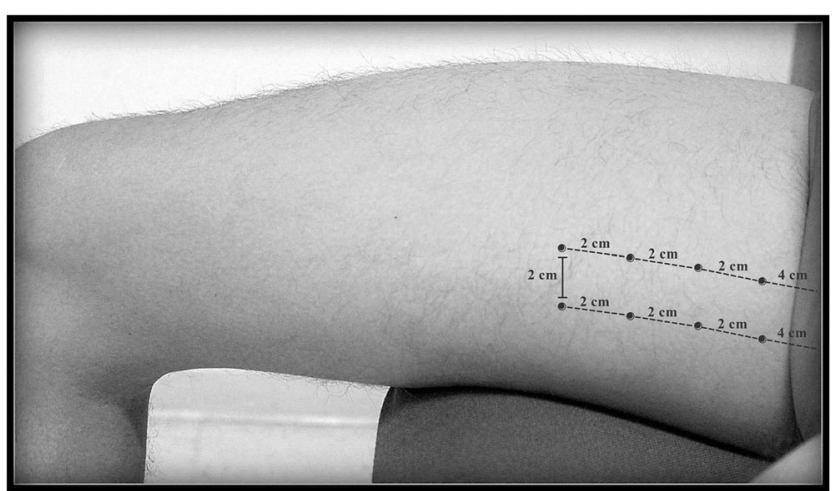

Fig. 2 Protocol of low-level laser therapy on the adductor magnus and adductor longus muscles applied at eight spots (spot size area of $0.028 \mathrm{~cm}^{2}$ ) consisting of two parallel lines (interspaced by $\sim 2 \mathrm{~cm}$ ) of four spots interspaced by $\sim 2 \mathrm{~cm}$, with the first point located around $4 \mathrm{~cm}$ from the groin. The circles show the representative points of LLLT application and the area size is not to scale

This linear laser array was applied eight times, thus irradiating 8 points of each leg, giving a total of 16 irradiated points per session with a total energy delivered of $48 \mathrm{~J}$ (i.e., $24 \mathrm{~J}$ per leg). The irradiation was performed in the contact mode with the laser probe held stationary with slight pressure at a $90^{\circ}$ angle on each of the 16 treatment points.

To ensure a double-blind design, the laser apparatus consisted of a switch with two possible options: one to "activate" and another to "inactivate" the laser (i.e., turned on but without laser irradiation). In both conditions, all machine feedback was disabled such as laser light and noise which could indicate whether the machine was performing laser irradiation or not. Before each LLLT irradiation treatment or placebo, a technician set the control unit of the laser to the active or placebo setting. Thereafter, the technician handed the preset laser to the assessor who applied the LLLT irradiation treatment or placebo. The technician was instructed not to disclose the type of treatment assigned to either the subject or researchers. During the experimental week, no researcher, subject, or team member involved in the laser/placebo application was informed of the active and inactive switch option positions, ensuring that the treatment allocation was hidden from the subjects, researchers, and observers.

\section{Anaerobic threshold determination}

To determine the anaerobic threshold (AnT), the athletes underwent four progressive bouts of 400-m freestyle swimming. The four $400-\mathrm{m}$ swimming stages corresponded to weak, moderate, strong, and maximal efforts and the velocities were $1.08 \pm 0.08,1.10 \pm 0.08,1.15 \pm 0.07$, and $1.25 \pm 0.14 \mathrm{~m} \mathrm{~s}^{-1}$, respectively. Blood samples $(25 \mu \mathrm{L})$ were collected from the earlobe immediately after each exercise stage for blood lactate analyses. The AnT corresponded to the exercise velocity at which an abrupt blood increase was observed, which was determined using a bi-segmented linear fit on the lactate-velocity relationship (i.e., second abrupt blood lactate increase).

\section{0-m Performance determination}

The athletes underwent a 200-m maximal free style swim, in a semi-Olympic $25-\mathrm{m}$ pool, starting the test in the water. The time to cover the $200 \mathrm{~m}$ was considered as the performance of $200 \mathrm{~m}$ (P200). This test was applied twice, before and after (48-h post) the LLLT + training intervention.

\section{0-s Crossbar jump test}

The 30 -s crossbar jump test (30CJ) is considered a classic water polo anaerobic-specific test [31, 32]. The $30 \mathrm{CJ}$ consists of performing the maximum number of jumps out of the water to touch the vertical bar of the water polo goal in $30 \mathrm{~s}$. The players were instructed to start the test in the fundamental floating position with their heads and shoulders just above the water, and after a beeping signal, to repeatedly jump out of the water and touch the vertical bar of the water polo goal
Table 1 All parameters of lowlevel laser therapy (LLLT)

\begin{tabular}{ll} 
Parameters & \\
\hline Wavelength & $810 \mathrm{~nm}$ (infrared) \\
Laser frequency & continuous optical output \\
Optical output & $100 \mathrm{~mW}$ \\
Spot size area & $0.028 \mathrm{~cm}^{2}$ \\
Power density & $3.57 \mathrm{~W} / \mathrm{cm}^{2}$ \\
Dose & $3 \mathrm{~J}$ per each point \\
Energy density & $107.14 \mathrm{~J} / \mathrm{cm}^{2}$ \\
Number of points & $16(8$ points per leg) \\
Muscles irradiated & adductor magnus and adductor longus muscles \\
Irradiation time & $30-\mathrm{s}$ \\
Total energy delivered & $48 \mathrm{~J}$ \\
Application mode & Probe held stationary in skin contact with a $90^{\circ}$ angle and slight pressure
\end{tabular}


Table 2 Values of body fat percentage ( $\%$ fat), fat mass, bone mass, bone mass density, lean mass, and lean mass plus bone mass (lean mass + bone mass) measured using the dual energy x-ray absorptiometry
(DEXA) in laser and placebo groups. The values are presented in mean \pm standard error of the mean ( $95 \%$ confidence interval)

\begin{tabular}{llllll}
\hline DEXA outcomes & Laser group & Placebo group & $P$ value & Effect size & Magnitude \\
\hline \% Fat (\%) & $19.2 \pm 1.2(16.5-21.9)$ & $19.8 \pm 1.0(17.5-22.0)$ & 0.72 & 0.09 & Trivial \\
Fat mass $(\mathrm{g})$ & $13,484.3 \pm 1311.5(10,517.5-16,451.1)$ & $12,371.7 \pm 1062.2(9968.8-14,774.4)$ & 0.52 & -0.14 & Trivial \\
Bone mass $(\mathrm{g})$ & $2473.9 \pm 169.3(2091.0-2856.9)$ & $2251.9 \pm 101.3(2021.3-2482.5)$ & 0.28 & -0.24 & Small \\
Bone mass density $\left(\mathrm{g} / \mathrm{cm}^{2}\right)$ & $1.10 \pm 0.04(1.02-1.18)$ & $1.06 \pm 0.03(0.99-1.12)$ & 0.34 & -0.24 & Small \\
Lean mass (g) & $53,424.9 \pm 3116.0(46,376.0-60,474.9)$ & $50,256.9 \pm 1727.7(46,348.6-54,165.1)$ & 0.39 & -0.19 & Trivial \\
Lean mass + bone mass $(\mathrm{g})$ & $55,898.9 \pm 3275.0(48,490.3-63,307.4)$ & $52,508.7 \pm 1799.9(48,437.2-56,580.3)$ & 0.38 & -0.20 & Small \\
\hline
\end{tabular}

with both hands. The validity and reliability of the 30CJ was described by Bampouras et al. [31, 32]. This procedure was repeated on each training day. The first test was taken as the baseline and the following tests were performed under the effect of the laser or placebo. The 30CJ was always applied after 5 min of warm-up, prior to the main training session.

\section{Training loads}

The weekly training loads were obtained using the sessionrating of perceived exertion (session-RPE) method as proposed by Foster et al. [33]. Thirty minutes after each daily training session, the perceived intensity was obtained from the Borg's scale as modified by Foster et al. [33]. The athletes were familiar with this method, having used the scale for a long time in their normal routines. All training load parameters were presented in arbitrary units (a.u.). The training loads were quantified by session-RPE, which corresponded to the product of post-training RPE and the duration of training in each exercise session.

\section{Measurement of the inflammatory and muscle damage markers}

On the first day of intervention (Tuesday), before the last training session (Saturday) and 24 and $48 \mathrm{~h}$ after the end of the training week, $\sim 5 \mathrm{~mL}$ of blood was drawn from the antecubital vein through venous puncture for analysis of blood cytokines (i.e., interleukin-1 beta, interleukin-10, and tumor necrosis factor-alpha) and muscular damage markers (i.e., creatine kinase and lactate desidrogenase). The blood samples were collected in Vacutainer ${ }^{\circledR}$ EDTA Tubes (Becton, Dickinson and Company Franklin Lakes, NJ, USA), that were immediately centrifuged at $3000 \mathrm{~g}$ per $10 \mathrm{~min}$. Thereafter, the plasma was separated and stored in $1.5-\mathrm{mL}$ tubes at $-80{ }^{\circ} \mathrm{C}$ until analysis.

Serum level of tumor necrosis factor-alpha (TNF- $\alpha)$, interleukin-1 beta (IL-1 $\beta$ ), and interleukin-10 (IL-10) were detected using commercial enzyme-linked immunosorbent assay kits (OptEIA; Becton, Dickinson and Company, Franklin Lakes, NJ, USA) according to the manufacturer's instructions. Serum was assayed in duplicates and intra-assay coefficients of variation were $9.5 \%(\mathrm{TNF}-\alpha), 8.8 \%$ (IL- $1 \beta)$, and $6.0 \%$ (IL-10), respectively.

Plasma creatine kinase (CK) activity and lactate dehydrogenase $(\mathrm{LDH})$ were analyzed using a specific enzymatic kit (Wiener-Laboratorios ${ }^{\circledR}$ SAIC, Rosario, Argentina, and Bioclin Quibasa ${ }^{\circledR}$, Santa Branca, Brazil, respectively) based on the manufacturer's instructions. The tests were read with a microplate spectrophotometer device (model SpectraMax Plus $384^{\circledR}$, Molecular Devices, Sunnyvale, CA, USA). The examiner was blinded to all analyses.

\section{Statistical analysis}

The normality of the data was confirmed using the Shapiro-Wilk test, which permitted the use of parametric

Table 3 The rating of perceived exertion (RPE) and session-RPE values measured during each exercise session during the week of LLLT intervention for both groups. Value in mean \pm standard error of the mean

\begin{tabular}{lllll}
\hline & Laser group - RPE (a.u.) & Laser group - session-RPE (a.u.) & Control group - RPE (a.u.) & Control group - session-RPE (a.u.) \\
\hline Tuesday & $6.3 \pm 0.5$ & $1280.9 \pm 109.4$ & $6.2 \pm 0.5$ & $1249.6 \pm 104.0$ \\
Wednesday & $5.7 \pm 0.6$ & $1140.0 \pm 120.4$ & $4.7 \pm 0.4$ & $940.0 \pm 79.2$ \\
Thursday & $6.7 \pm 0.5$ & $1333.3 \pm 98.7$ & $6.3 \pm 0.5$ & $1255.6 \pm 96.3$ \\
Friday & $6.1 \pm 0.7$ & $1210.0 \pm 135.3$ & $6.2 \pm 0.4$ & $1240.0 \pm 89.7$ \\
Saturday & $4.1 \pm 0.8$ & $731.3 \pm 148.6$ & $3.7 \pm 0.3$ & $596.3 \pm 92.5$ \\
\hline
\end{tabular}


Table 4 Results from 30-s crossbar jump test (30CJ) measured before low-level laser therapy intervention and during each day of intervention. The values are presented in mean \pm standard error of the mean ( $95 \%$ confidence interval)

\begin{tabular}{cllllll}
\hline & & Pre & Day 1 & Day 2 & Day 3 & Day 4 \\
\hline Laser & 30CJ (Jump) & $26.0 \pm 0.9(24.0-28.0)$ & $26.6 \pm 0.6(25.3-27.9)$ & $26.7 \pm 0.5(25.5-27.9)$ & $27.5 \pm 0.7(26.0-29.0)$ & $28.0 \pm 0.8(26.1-29.8)$ \\
group & 30CJ (\% change & $100.0 \pm 0.0(0.0-0.0)$ & $102.8 \pm 1.9(100.0-105.6)$ & $103.7 \pm 3.9(97.5-110.0)$ & $106.9 \pm 4.6(99.4-114.5)$ & $108.7 \pm 4.6(100.6-116.8)$ \\
& from pre) & & & & & \\
Placebo & 30CJ (Jump) & $25.9 \pm 0.6(24.5-27.3)$ & $25.9 \pm 0.6(24.5-27.3)$ & $26.0 \pm 0.8(24.1-27.8)$ & $26.3 \pm 0.7(24.6-28.0)$ & $26.3 \pm 0.8(24.5-28.0)$ \\
group & 30CJ (\% change & $100.0 \pm 0.0(0.0-0.0)$ & $100.0 \pm 1.3(97.2-102.8)$ & $100.3 \pm 1.7(94.1-106.6)$ & $101.6 \pm 2.1(94.1-109.2)$ & $101.8 \pm 2.9(93.7-109.9)$ \\
& from pre) & & & & &
\end{tabular}

analysis and mean \pm standard error of mean to present the results. The $95 \%$ confidence interval $(95 \% \mathrm{CI})$ was also presented. The independent $t$ test was used to compare the data from DEXA between groups. Twoway analysis of variance (ANOVA) (groups $\times$ time) for repeated measures was used to compare the values measured in both groups, before and after the LLLT intervention. In addition, Mauchly's sphericity test was applied to the data and sphericity was assumed to be violated when the $F$ test was significant. In case of sphericity violation, the Greenhouse-Geisser Epsilion correction was used. Analyses were completed by using the "LSD" post hoc test. The effect size (ES) obtained in each statistical analysis are also presented and interpreted as proposed by Hopkins (www.sportsci.org/ resource/stats), with $\mathrm{ES}<0.2$ considered as trivial, small between 0.2 and 0.5 , moderate between 0.6 and 1.1 , large between 1.2 and 1.9 , and very large $>2.0$. In all cases, statistical significance was set at $P<0.05$. Statistical analyses were performed using the software package SPSS version 16.0 (SPSS Inc., Chicago, IL, USA).

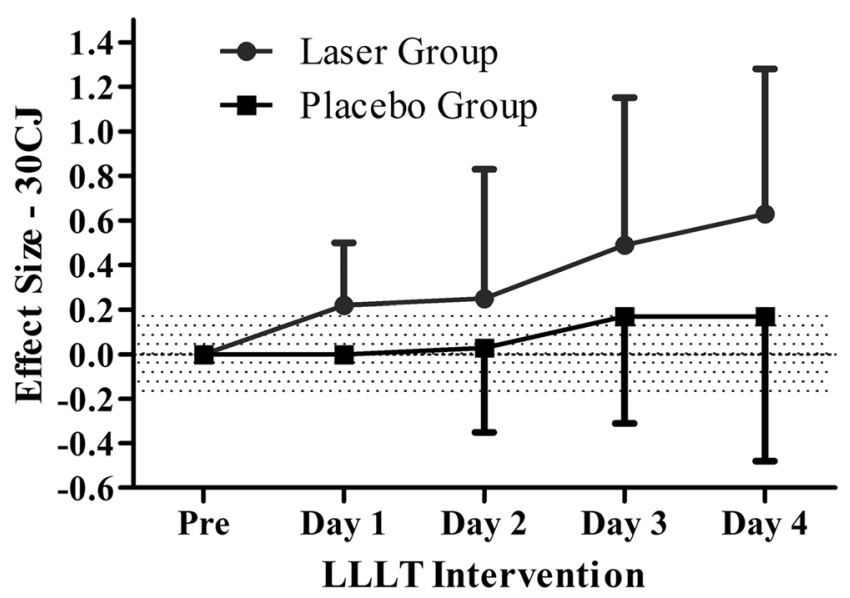

Fig 3 Effect size in mean and $95 \%$ confidence interval for CJ-30 changes for the placebo and LLLT groups

\section{Results}

The values of body composition measured using DEXA are presented in Table 2. No differences $(P>0.05)$ between groups were observed.

The training load quantified by session-RPE did not differ statistically $(P>0.05)$ between groups. These values are presented in Table 3.

There was no difference $(P>0.05 ; \mathrm{ES}=0.29)$ between the laser and placebo groups for the 200-m performance pre $(154.2 \pm 12.2$ and $155.1 \pm 6.7 \mathrm{~s}$, respectively) and post $(152.6 \pm 13.8$ and $155.9 \pm 6.7 \mathrm{~s}$, respectively) the intervention week. However, small to moderate effects were found for the LLLT group in the 30-CJ performance across the measures (Table 4). As can be seen in Table 4, ES increased through days 1 to 4 (Fig. 3). This effect was not found in the placebo group, which maintained performance throughout the experimental week (within the trivial change zone) (Fig. 3 and Table 6).

The results of interleukin-1 beta (IL-1 $\beta$ ), interleukin-10 (IL-10), tumor necrosis factor alpha (TNF- $\alpha$ ), creatine kinase (CK), lactate dehydrogenase (LDH), ratio IL-10/TNF- $\alpha$, and TNF- $\alpha /$ IL-10 ratio for both groups measured at baseline (pre) and immediately, 24- and 48-h after the final LLLT intervention are presented in Table 5. The values of percentage changes in relation to baseline for these variables are presented in Figs. 4 and 5. There were no differences $(P>0.05)$ between groups in the inflammatory and muscle damage markers between the pre and post experimental week. However, there were within group differences in the changes in IL- $1 \beta$ $(P=0.016$, statistical power $=96.8 \%)$ and TNF- $\alpha 48 \mathrm{~h}$ $(P=0.010$, statistical power $=94.8 \%)$ after the final LLLT intervention compared to pre, 0 , and $24 \mathrm{~h}$. A significant decrement $(P<0.05)$ in $\mathrm{CK}$ concentration $(P=0.049$, statistical power $=64.1 \%$ ) was also observed in the LLLT group post experimental week compared to the baseline and immediately after the final LLLT intervention. Regarding the effect size of the changes in cytokine concentration, moderate effects were found in the pre to post changes in IL-1 $\beta$, IL-10, and LDH between groups (Table 6). 
Table 5 Results from interleukin 1 beta (IL-1 $\beta$ ), interleukin 10 (IL-10), tumor necrosis factor alpha $(\mathrm{TNF}-\alpha)$, creatine kinase $(\mathrm{CK})$, lactate dehydrogenase (LDH), ratio IL-10/TNF- $\alpha$ and ratio TNF- $\alpha /$ IL-10 for both groups measured at baseline (pre) and immediately, 24 and 48 after the last LLLT intervention. The values are presented in mean \pm standard error of the mean ( $95 \%$ confidence interval)

\begin{tabular}{|c|c|c|c|c|c|}
\hline & & Pre & Post & $24 \mathrm{~h}$ & $48 \mathrm{~h}$ \\
\hline \multirow{7}{*}{$\begin{array}{l}\text { Laser } \\
\text { group }\end{array}$} & $\mathrm{IL}-1 \beta\left(\mathrm{pg} \mathrm{mL}^{-1}\right)$ & $1.58 \pm 0.10(1.52-1.64)$ & $1.46 \pm 0.09(1.41-1.52)$ & $1.48 \pm 0.06^{\mathrm{ab}}(1.43-1.53)$ & $1.99 \pm 0.66^{\mathrm{bc}}(1.53-2.44)$ \\
\hline & IL-10 $\left(\mathrm{pg} \mathrm{mL}^{-1}\right)$ & $3.94 \pm 1.94(2.77-5.12)$ & $3.18 \pm 1.40(2.18-4.17)$ & $3.49 \pm 1.39(2.49-4.49)$ & $4.00 \pm 1.71(2.88-5.12)$ \\
\hline & TNF- $\alpha\left(p g \mathrm{~mL}^{-1}\right)$ & $1.43 \pm 0.21(1.24-1.62)$ & $1.32 \pm 0.20(1.13-1.67)$ & $1.49 \pm 0.17(1.32-1.67)$ & $2.04 \pm 0.68^{\mathrm{abc}}(1.58-2.49)$ \\
\hline & $\mathrm{CK}(\mathrm{IU} / \mathrm{L})$ & $125.26 \pm 70.25(79.63-170.88)$ & $114.06 \pm 56.43(75.99-152.14)$ & $84.30 \pm 33.36(59.34-109.26)$ & $60.76 \pm 40.66^{\mathrm{ab}}(29.35-92.17)$ \\
\hline & $\mathrm{LDH}$ & $87.55 \pm 25.07(71.31-103.78)$ & $79.03 \pm 29.51(60.37-97.69)$ & $83.28 \pm 14.21(73.30-93.26)$ & $99.04 \pm 33.26(81.44-116.65)$ \\
\hline & Ratio IL-10/TNF- $\alpha$ & $2.57 \pm 0.42(1.66-3.47)$ & $2.50 \pm 0.40(1.63-3.38)$ & $2.41 \pm 0.33(1.69-3.13)$ & $2.14 \pm 0.30(0.49-2.78)$ \\
\hline & Ratio TNF- $\alpha /$ IL-10 & $0.446 \pm 0.063(0.311-0.581)$ & $0.444 \pm 0.064(0.360-0.582)$ & $0.453 \pm 0.057(0.329-0.576)$ & $0.534 \pm 0.0644(0.397-0.671)$ \\
\hline \multirow{7}{*}{$\begin{array}{l}\text { Placebo } \\
\text { group }\end{array}$} & $\mathrm{IL}-1 \beta\left(\mathrm{pg} \mathrm{mL}^{-1}\right)$ & $1.56 \pm 0.07(1.50-1.63)$ & $1.50 \pm 0.06(1.44-1.56)$ & $1.49 \pm 0.08(1.44-1.54)$ & $1.99 \pm 0.66(1.38-2.34)$ \\
\hline & IL-10 (pg mL $\left.{ }^{-1}\right)$ & $2.96 \pm 1.32(1.78-4.13)$ & $3.22 \pm 1.42(2.23-4.22)$ & $3.78 \pm 1.43(2.78-4.78)$ & $4.24 \pm 1.43(3.13-5.36)$ \\
\hline & TNF- $\alpha\left(p g \mathrm{~mL}^{-1}\right)$ & $1.58 \pm 0.29(1.39-1.77)$ & $1.43 \pm 0.29(1.24-1.61)$ & $1.61 \pm 0.28(1.44-1.79)$ & $1.77 \pm 0.51(1.31-2.22)$ \\
\hline & CK (i.u./L) & $97.30 \pm 58.32(51.68-142.92)$ & $107.66 \pm 51.22(69.58-145.74)$ & $82.22 \pm 37.17(57.26-107.17)$ & $79.27 \pm 47.93(47.86-110.68)$ \\
\hline & $\mathrm{LDH}$ & $64.12 \pm 20.65(47.91-80.37)$ & $81.17 \pm 22.90(62.51-99.83)$ & $82.34 \pm 14.05(72.36-92.33)$ & $84.79 \pm 11.66(67.18-102.40)$ \\
\hline & Ratio IL-10/TNF- $\alpha$ & $2.07 \pm 0.45(1.10-3.04)$ & $2.44 \pm 0.43(1.50-3.37)$ & $2.54 \pm 0.36(1.77-3.31)$ & $2.54 \pm 0.32(1.85-3.23)$ \\
\hline & Ratio TNF- $\alpha / \mathrm{IL}-10$ & $0.572 \pm 0.067(0.428-0.717)$ & $0.504 \pm 0.068(0.356-0.651)$ & $0.459 \pm 0.061(0.327-0.591)$ & $0.433 \pm 0.068(0.286-0.580)$ \\
\hline
\end{tabular}

${ }^{\text {a }} P<0.05$ to pre in the same group

${ }^{\mathrm{b}} P<0.05$ to post in the same group

${ }^{\mathrm{c}} P<0.05$ to $24 \mathrm{~h}$ in the same group

\section{Discussion}

In the present study, we demonstrated that high training loads were not able to produce significant effects in athletic performance in male water polo players; however, alterations in the biochemical and inflammatory mediators were observed. Although the performance tests did not demonstrate significant differences $(P<0.05)$, in the laser-treated group the players swam the $200 \mathrm{~m}$ around $1.1 \%$ faster while the 30-CJ after LLLT improved around $9 \%$. This concurs with Hopkin's findings [34] that sometimes conventional statistical analysis is not sensitive enough to detect improvements in sport performance and therefore, we added the analysis using effect size, which enables a complementary analysis of magnitude of the difference between groups [35]. In addition, LLLT was able to negate the alterations precipitated by high training loads in young male water polo players.
The application of LLLT in musculoskeletal fatigue processes to decrease muscle damage markers and inflammatory processes is relatively new and there is a wide variation in energy, power, power density, and irradiation times [16, 18]; the optimal parameters of application are not yet fully elucidated. However, some studies in the literature [18, 19], using similar laser dosimetry to that used in the current study (i.e., $3 \mathrm{~J}$ per point), reported beneficial effects on tissue repair in a shorter time in injured muscles, as well as a delay in the onset of skeletal muscle fatigue in high-intensity exercises [24, 36], evidencing the effectiveness of the dosage used in LLLT treatment. Moreover, in a systematic review, Borsa et al. [18] reported that diodes emitting in the near infrared spectral range are best suited for treating deep soft tissue disorders due to these wavelengths transmitting light energy from 2 to $4 \mathrm{~cm}$ beyond the skin interface, similar to the laser wavelength used in the current study (i.e., $810 \mathrm{~nm}$ ); while diodes with wavelengths ranging from 400 to $700 \mathrm{~nm}$ have poorer light
Fig 4 Percentage change from baseline ( $\%$ change from pre) for creatine kinase $(\mathrm{CK})$ and lactate dehydrogenase (LDH) measured in both groups at baseline and immediately, 24 and $48 \mathrm{~h}$ after the final LLLT intervention. $a$ $P<0.05$ compared to pre in the same group. Error bars represent standard error of the mean
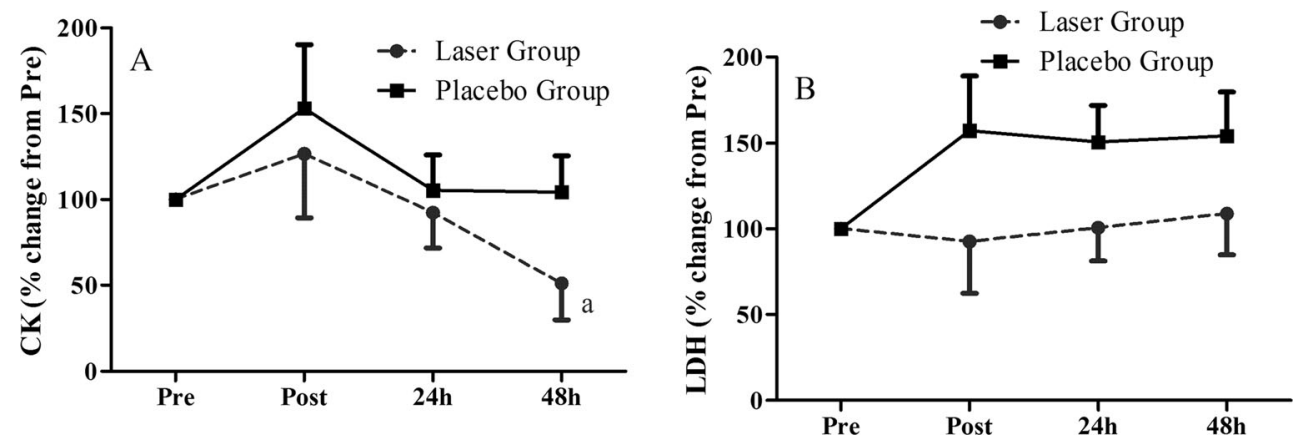

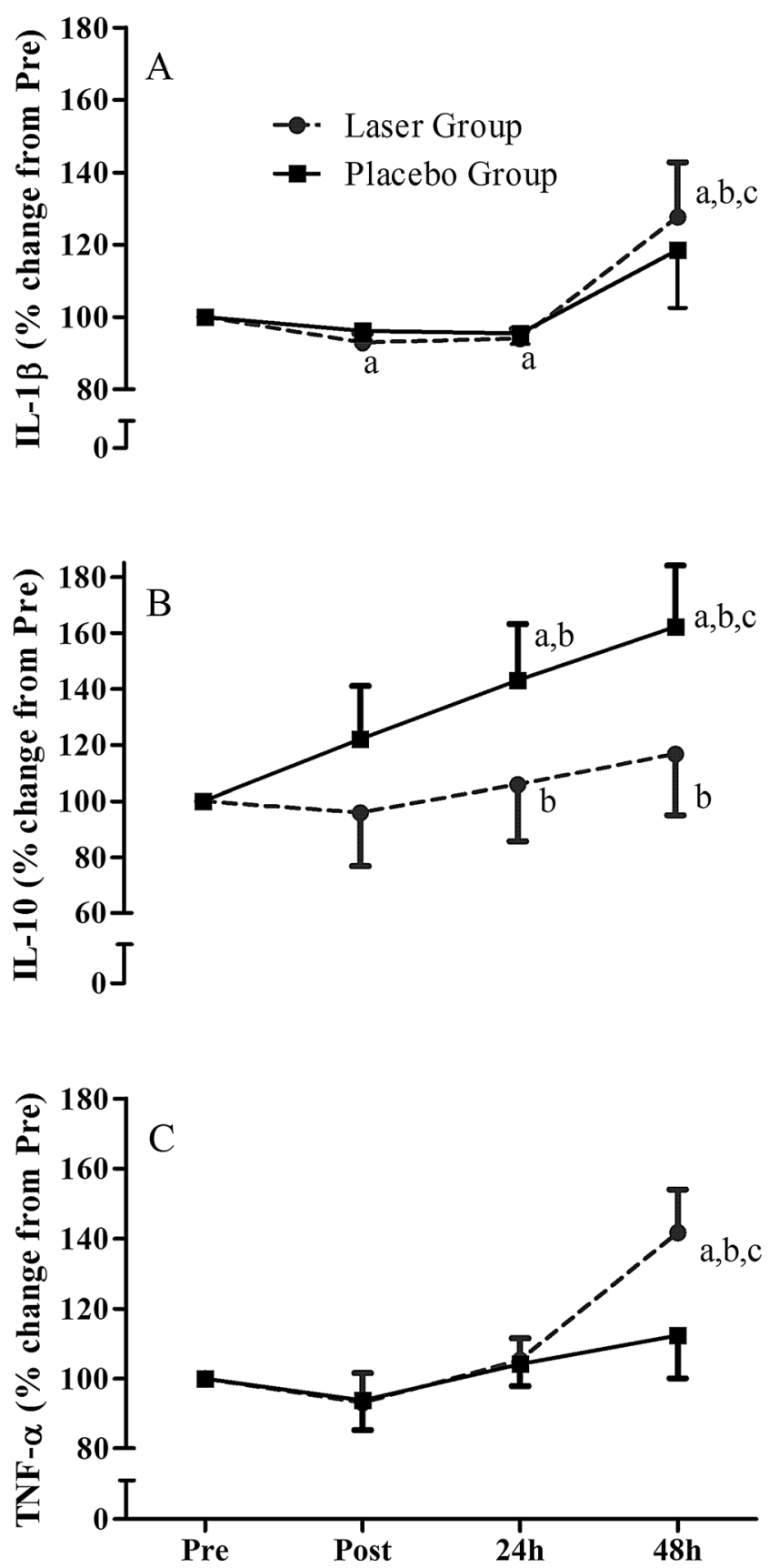

Fig 5 Percentage change from baseline (\% change from pre) for interleukin 1 beta (IL-1 $\beta$ ), interleukin 10 (IL-10), and tumor necrosis factor alpha (TNF- $\alpha)$, measured in both groups at baseline and immediately, 24 and $48 \mathrm{~h}$ after the final LLLT intervention. $a P<0.05$ to pre in the same group; $b P<0.05$ to post in the same group; $c P<0.05$ to $24 \mathrm{~h}$ in the same group. Error bars represent standard error of the mean

penetration $(\sim 1 \mathrm{~cm})$ and transmit light energy only to the epidermal and dermal tissue layers [18].

Prevention of muscle damage and inflammatory reaction are important issues during training periods and after competitive events, since they are associated with loss of function and underperformance. Inflammatory cytokines seem to play important roles in attracting inflammatory cells into skeletal muscle leading to additional muscle damage and sustained loss of performance [12, 13]. In the present study, markers of muscle damage (LDH and CK activity) were not significantly elevated after 1 week of training in either group, indicating that the athletes did not experience extensive muscle damage from their typical training schedule. The training load outcome measured daily was high (session-RPE average of around 1050 arbitrary units per day) mainly due to the high time expended in each training session (i.e., $~ 3-4 \mathrm{~h}$ ). Nevertheless, when percentage changes in $\mathrm{CK}$ activity were observed over time after the final training session, it was observed that immediate and late muscle damage seemed to be partially avoided in the laser group. This is in agreement with other authors who reported that both laser and LED therapies were able to reduce exercise-induced release of CK $[22,23$, $37,38]$. The increase in IL-1 $\beta$ and TNF- $\alpha$ levels at $48 \mathrm{~h}$ suggests that some degree of inflammation may develop after ending laser treatment even in the absence of signs of muscle damage, such as biochemical markers or loss of function.

Increased inflammatory reactions in response to increasing training loads have been reported by some authors in handball and cycling athletes [10] while others did not find any significant alterations in inflammatory mediators during preseason training in sports teams $[1,3,39]$. IL- $1 \beta$ and TNF- $\alpha$ are the most important inflammatory cytokines, specifically in the early phases of the inflammatory process, and increased circulating levels can be observed in some athletes after intense or high volume exercises, such as reported during official competitions $[9,40]$.

High-intensity eccentric contractions may damage muscle fibers and connective tissue (i.e., perimysium and endomysium) and trigger an inflammatory response highlighted by muscle and leukocyte release of IL- $1 \beta$ and TNF- $\alpha[12$, 13]. These cytokines can activate inflammatory cells such as neutrophils and macrophages producing secondary muscle damage due to overproduction of free radicals up to 7 days after the exercise [41, 42]. In experimental studies, TNF- $\alpha$ was associated with pain, recruitment of neutrophils, and oxidative stress in response to a protocol of exercise-induced muscle damage [41]. Delayed muscle damage was also associated with increased levels of IL- $1 \beta$ and leukocyte recruitment starting immediately after high training loads or prolonged running, peaking after $24 \mathrm{~h}$ and continuing for up to 7 days post-exercise [11, 13, 42]. However, well-trained team athletes did not experience increased resting levels of inflammatory cytokines under their typical training programs $[1,3,39]$, only when high loads were imposed during competitive events $[9,40]$. On the other hand, IL-10 is a classic anti-inflammatory cytokine produced in order to down modulate the inflammatory response, especially TNF- $\alpha$ production, and protect host tissues from inflammatory injury [43]. Typically, IL-10 circulating levels rise with cumulative 
Table 6 Values of effect size $( \pm 95 \% \mathrm{CI})$ for comparison between baseline versus immediately post LLLT intervention $(0 \mathrm{~h})$ to 200 -m performance, interleukins-1 beta (IL-1 $\beta$ ), and -10 (IL-10), tumor necrosis factor alpha (TNF- $\alpha$ ), creatine kinase, and lactate dehydrogenase (LDH)

\begin{tabular}{|c|c|c|c|c|c|c|}
\hline $\begin{array}{l}\text { Baseline versus } \\
\text { immediately post }\end{array}$ & P200 & IL-1 $\beta$ & IL-10 & TNF- $\alpha$ & $\mathrm{CK}$ & LDH \\
\hline Laser & $\begin{array}{l}-0.12( \pm 0.22) \\
\text { (Trivial magnitude) }\end{array}$ & $\begin{array}{l}-1.11( \pm 0.80) \\
\text { (Moderate magnitude) }\end{array}$ & $\begin{array}{l}-0.36( \pm 0.75) \\
\text { (Small magnitude) }\end{array}$ & $\begin{array}{l}-0.49( \pm 0.67) \\
\text { (Small magnitude) }\end{array}$ & $\begin{array}{l}-0.15( \pm 0.67) \\
\text { (Trivial magnitude) }\end{array}$ & $\begin{array}{l}-0.24( \pm 0.46) \\
\text { (Small magnitude) }\end{array}$ \\
\hline Placebo & $\begin{array}{l}0.11( \pm 0.29) \\
\text { (Trivial magnitude) }\end{array}$ & $\begin{array}{l}-0.77( \pm 0.55) \\
\text { (Moderate magnitude) }\end{array}$ & $\begin{array}{l}0.20( \pm 0.88) \\
\text { (Small magnitude) }\end{array}$ & $\begin{array}{l}-0.50( \pm 0.80) \\
\text { (Small magnitude) }\end{array}$ & $\begin{array}{l}0.16( \pm 1.10) \\
\text { (Trivial magnitude) }\end{array}$ & $\begin{array}{l}0.60( \pm 1.03) \\
\text { (Moderate magnitude) }\end{array}$ \\
\hline $\begin{array}{l}\text { Laser versus } \\
\quad \text { Placebo }\end{array}$ & $\begin{array}{l}0.23( \pm 0.32) \\
\text { (Small magnitude) }\end{array}$ & $\begin{array}{l}0.75( \pm 1.10) \\
\text { (Moderate magnitude) }\end{array}$ & $\begin{array}{l}0.68( \pm 1.24) \\
\text { (Moderate magnitude) }\end{array}$ & $\begin{array}{l}-0.14( \pm 1.10) \\
\text { (Trivial magnitude) }\end{array}$ & $\begin{array}{l}0.36( \pm 1.20) \\
\text { (Small magnitude) }\end{array}$ & $\begin{array}{l}0.87( \pm 0.93) \\
\text { (Moderate magnitude) }\end{array}$ \\
\hline
\end{tabular}

increased training loads and immediately after high-intensity efforts [5]. In the present study, no significant changes in IL10 were observed immediately after exercise, suggesting that small or non-significant muscle damage (and acute secretion of inflammatory mediators) may have occurred. However, the percentage of changes in IL-10 concentration at 24 and $48 \mathrm{~h}$ suggest the occurrence of a delayed anti-inflammatory response in the placebo group, which may partially explain the lack of increase in TNF- $\alpha$ levels.

One of the mechanisms underlying prevention of induced muscle damage by phototherapy may be its anti-inflammatory effects. Experimental models have demonstrated that phototherapy can decrease IL-1 $\beta$ expression during repair of injured skeletal muscle [17], decrease IL- $1 \beta$ and TNF- $\alpha$ release after a high-load resistance training program and inhibit inflammatory cell migration into skeletal muscle after intense exercise [44]. In human studies, phototherapy reduced muscle damage markers (CK and LDH activity) [36, 38], delayed onset muscle soreness [21], pain threshold [21], and inflammatory mediators (i.e., PCR) after an intense bout of exercise $[22,23]$. The results of the present study are in agreement with other studies that reported increased levels of CK immediately after a bout of intense exercise, but there was a faster clearance of $\mathrm{CK}$ levels during recovery in individuals who received phototherapy $[22,23,37]$. Surprisingly, the antiinflammatory effects of laser irradiation seemed not to be effective in blunting the delayed inflammatory reaction over the time-course of recovery ( 24 and $48 \mathrm{~h}$ ) although it may blunt the IL-10/TNF- $\alpha$ ratio.

In addition, increased activity of the cytochrome c oxidase enzyme has been reported after irradiation with red and nearinfrared lights $[25,45]$, which can lead to "extra" adenosine triphosphate synthesis, explaining the cumulative effect of LLLT in 30-CJ (Fig. 3 and Table 4) and other cellular effects. In addition, the increased activity of the cytochrome c oxidase has been considered the key factor to explain how LLLT can enhance performance and protect skeletal muscles against fatigue development and tissue damage $[25,45]$. The measurement of inflammatory mediators and muscle damage markers in blood serum and not in muscular tissue may be considered a limitation of the study, since the local effect of LLLT intervention on muscle may not be detected in blood. Furthermore, the small area covered by the single-diode LLLT can also be considered a limitation, whereas the use of multi-diode (i.e., cluster) therapy seems to be more effective [46] and cover a wider muscular area. However, we tried to reduce this influence by increasing the number of irradiated points in each leg (i.e., eight points per leg), but only for muscles engaged in eggbeater kicks.

In summary, our results show that low-level laser therapy intervention resulted in non-significant, but small to moderate effects on inflammatory and muscle damage markers, mainly in CK, IL-10, and TNF- $\alpha$ and moderate effects on performance in water polo players. In addition, the lack of positive results could be due to the small area covered by irradiation and, therefore, a multi-diode laser and additional muscle groups such as the upper limbs should be considered in future studies.

\section{Compliance with ethical standards}

Conflict of interest The authors declare that they have no competing interests.

\section{References}

1. Brunelli DT, Borin JP, Rodrigues A, Bonganha V, Prestes J, Montagner PC, Cavaglieri CR (2012) Immune responses, upper respiratory illness symptoms, and load changes in young athletes during the preparatory period of the training periodization. Open Access J Sports Med 3:43-49. doi:10.2147/OAJSM.S30962

2. Coutts AJ, Wallace LK, Slattery KM (2007) Monitoring changes in performance, physiology, biochemistry, and psychology during overreaching and recovery in triathletes. Int J Sports Med 28(2): 125-134. doi:10.1055/s-2006-924146

3. Dias R, Frollini AB, Brunelli DT, Yamada AK, Leite RD, Simoes RA, Salles GS, Trevisan D, Pellegrinotti IL, de Castro CM, Alves SC, Verlengia R, Borin JP, Prestes J, Cavaglieri CR (2011) Immune parameters, symptoms of upper respiratory tract infections, and 
training-load indicators in volleyball athletes. Int J Gen Med 4:837844. doi:10.2147/IJGM.S24402

4. Docherty D, Sporer B (2000) A proposed model for examining the interference phenomenon between concurrent aerobic and strength training. Sports Med 30(6):385-394

5. Cox AJ, Pyne DB, Saunders PU, Callister R, Gleeson M (2007) Cytokine responses to treadmill running in healthy and illnessprone athletes. Med Sci Sports Exerc 39(11):1918-1926. doi:10. 1249/mss.0b013e318149f2aa

6. Helgerud J, Rodas G, Kemi OJ, Hoff J (2011) Strength and endurance in elite football players. Int J Sports Med 32(9):677-682. doi: 10.1055/s-0031-1275742

7. Fry RW, Morton AR, Keast D (1992) Acute intensive interval training and T-lymphocyte function. Med Sci Sports Exerc 24(3):339345

8. Smith LL (2000) Cytokine hypothesis of overtraining: a physiological adaptation to excessive stress? Med Sci Sports Exerc 32(2): 317-331

9. Andersson H, Bohn SK, Raastad T, Paulsen G, Blomhoff R, Kadi F (2010) Differences in the inflammatory plasma cytokine response following two elite female soccer games separated by a 72 -h recovery. Scand J Med Sci Sports 20(5):740-747. doi:10.1111/j.16000838.2009.00989.x

10. Concepcion-Huertas M, Chirosa LJ, De Haro T, Chirosa IJ, Romero V, Aguilar-Martinez D, Leonardo-Mendonca RC, Doerrier C, Escames G, Acuna-Castroviejo D (2013) Changes in the redox status and inflammatory response in handball players during oneyear of competition and training. J Sports Sci 31(11):1197-1207. doi:10.1080/02640414.2013.773404

11. Paulsen G, Crameri R, Benestad HB, Fjeld JG, Morkrid L, Hallen J, Raastad T (2010) Time course of leukocyte accumulation in human muscle after eccentric exercise. Med Sci Sports Exerc 42(1):75-85. doi:10.1249/MSS.0b013e3181ac7adb

12. Paulsen G, Mikkelsen UR, Raastad T, Peake JM (2012) Leucocytes, cytokines and satellite cells: what role do they play in muscle damage and regeneration following eccentric exercise? Exerc Immunol Rev 18:42-97

13. Fielding RA, Manfredi TJ, Ding W, Fiatarone MA, Evans WJ, Cannon JG (1993) Acute phase response in exercise. III. Neutrophil and IL-1 beta accumulation in skeletal muscle. Am J Physiol 265(1 Pt 2):R166-172

14. Ascensao A, Leite M, Rebelo AN, Magalhaes S, Magalhaes J (2011) Effects of cold water immersion on the recovery of physical performance and muscle damage following a one-off soccer match. J Sports Sci 29(3):217-225. doi:10.1080/02640414.2010.526132

15. Franchini E, Yuri Takito M, Yuzo Nakamura F, Ayumi Matsushigue K, Peduti Dal'Molin Kiss MA (2003) Effects of recovery type after a judo combat on blood lactate removal and on performance in an intermittent anaerobic task. J Sports Med Phys Fitness 43(4):424431

16. Leal-Junior EC, Vanin AA, Miranda EF, de Carvalho PT, Dal Corso S, Bjordal JM (2015) Effect of phototherapy (low-level laser therapy and light-emitting diode therapy) on exercise performance and markers of exercise recovery: a systematic review with meta-analysis. Lasers Med Sci 30(2):925-939. doi:10.1007/s10103-0131465-4

17. Fernandes KP, Alves AN, Nunes FD, Souza NH, Silva JA Jr, Bussadori SK, Ferrari RA (2013) Effect of photobiomodulation on expression of IL-1beta in skeletal muscle following acute injury. Lasers Med Sci 28(3):1043-1046. doi:10.1007/s10103-012-1233$\mathrm{x}$

18. Borsa PA, Larkin KA, True JM (2013) Does phototherapy enhance skeletal muscle contractile function and postexercise recovery? A systematic review. J Athl Training 48(1):57-67. doi:10.4085/10626050-48.1.12
19. Leal Junior EC, Lopes-Martins RA, Vanin AA, Baroni BM, Grosselli D, De Marchi T, Iversen VV, Bjordal JM (2009) Effect of $830 \mathrm{~nm}$ low-level laser therapy in exercise-induced skeletal muscle fatigue in humans. Lasers Med Sci 24(3):425-431. doi:10.1007/ s10103-008-0592-9

20. Leal EC, de Godoi V, Mancalossi JL, Rossi RP, De Marchi T, Parente M, Grosselli D, Generosi RA, Basso M, Frigo L, Tomazoni SS, Bjordal JM, Lopes-Martins RAB (2011) Comparison between cold water immersion therapy (CWIT) and light emitting diode therapy (LEDT) in short-term skeletal muscle recovery after high-intensity exercise in athletes-preliminary results. Lasers Med Sci 26(4):493-501. doi:10.1007/s10103-0100866-x

21. Antonialli FC, De Marchi T, Tomazoni SS, Vanin AA, dos Santos GV, de Paiva PR, Pinto HD, Miranda EF, de Tarso C, de Carvalho P, Leal-Junior EC (2014) Phototherapy in skeletal muscle performance and recovery after exercise: effect of combination of superpulsed laser and light-emitting diodes. Lasers Med Sci 29(6):19671976. doi:10.1007/s10103-014-1611-7

22. Leal Junior EC, Lopes-Martins RA, Frigo L, De Marchi T, Ross RP, de Godoi V, Tomazoni SS, Silva DP, Basso M, Filho PL, de Valls CF, Iversen VV, Bjordal JM (2010) Effects of low-level laser therapy (LLLT) in the development of exercise-induced skeletal muscle fatigue and changes in biochemical markers related to postexercise recovery. J Orthop Sports Phys Ther 40(8):524-532. doi: 10.2519/jospt.2010.3294

23. Leal Junior EC, Lopes-Martins RA, Rossi RP, De Marchi T, Baroni BM, de Godoi V, Marcos RL, Ramos L, Bjordal JM (2009) Effect of cluster multi-diode light emitting diode therapy (LEDT) on exercise-induced skeletal muscle fatigue and skeletal muscle recovery in humans. Lasers Surg Med 41(8):572-577. doi:10.1002/lsm. 20810

24. Miranda EF, de Oliveira LV, Antonialli FC, Vanin AA, de Carvalho PT, Leal-Junior EC (2015) Phototherapy with combination of super-pulsed laser and light-emitting diodes is beneficial in improvement of muscular performance (strength and muscular endurance), dyspnea, and fatigue sensation in patients with chronic obstructive pulmonary disease. Lasers Med Sci 30(1):437-443. doi: 10.1007/s10103-014-1690-5

25. Albuquerque-Pontes GM, Vieira Rde P, Tomazoni SS, Caires CO, Nemeth V, Vanin AA, Santos LA, Pinto HD, Marcos RL, Bjordal JM, de Carvalho PT, Leal-Junior EC (2015) Effect of pre-irradiation with different doses, wavelengths, and application intervals of lowlevel laser therapy on cytochrome $\mathrm{c}$ oxidase activity in intact skeletal muscle of rats. Lasers Med Sci 30(1):59-66. doi:10.1007/ s10103-014-1616-2

26. Melchiorri G, Castagna C, Sorge R, Bonifazi M (2010) Game activity and blood lactate in men's elite water-polo players. J Strength Cond Res 24(10):2647-2651. doi:10.1519/JSC. 0b013e3181e3486b

27. Royal KA, Farrow D, Mujika I, Halson SL, Pyne D, Abernethy B (2006) The effects of fatigue on decision making and shooting skill performance in water polo players. J Sports Sci 24(8):807-815. doi: $10.1080 / 02640410500188928$

28. Stirn I, Strmecki J, Strojnik V (2014) The examination of different tests for the evaluation of the efficiency of the eggbeater kicks. J Hum Kinet 41:215-226. doi:10.2478/hukin-2014-0049

29. Oliveira N, Fernandes RJ, Sarmento M, Liberal S, Figueiredo PA, Gonçalves P, Villas-Boas JP (2010) Muscle activity during the typical water polo eggbeater kick. Int J Aquat Res Ed 4:163-174

30. Franic M, Ivkovic A, Rudic R (2007) Injuries in water polo. Croat Med J 48(3):281-288

31. Bampouras TM, Marrin K (2009) Comparison of two anaerobic water polo-specific tests with the Wingate test. J Strength Cond Res 23(1):336-340. doi:10.1519/JSC.0b013e3181876ad0 
32. Bampouras TM, Marrin K (2010) Reliability of the 30-s crossbar jumps water polo test. Serbian Journal of Sports Sciences 4(2):6973

33. Foster C, Florhaug JA, Franklin J, Gottschall L, Hrovatin LA, Parker S, Doleshal P, Dodge C (2001) A new approach to monitoring exercise training. J Strength Cond Res 15(1):109-115

34. Hopkins WG (2000) Measures of reliability in sports medicine and science. Sports Med 30(1):1-15

35. Sullivan GM, Feinn R (2012) Using effect size - or why the P value is not enough. J Grad Med Educ 4(3):279-282. doi:10.4300/ JGME-D-12-00156.1

36. De Marchi T, Leal Junior EC, Bortoli C, Tomazoni SS, LopesMartins RA, Salvador M (2012) Low-level laser therapy (LLLT) in human progressive-intensity running: effects on exercise performance, skeletal muscle status, and oxidative stress. Lasers Med Sci 27(1):231-236. doi:10.1007/s10103-011-0955-5

37. Felismino AS, Costa EC, Aoki MS, Ferraresi C, de Araujo Moura Lemos TM, de Brito Vieira WH (2014) Effect of low-level laser therapy $(808 \mathrm{~nm})$ on markers of muscle damage: a randomized double-blind placebo-controlled trial. Lasers Med Sci 29(3):933938. doi:10.1007/s10103-013-1430-2

38. Baroni BM, Leal ECP, De Marchi T, Lopes AL, Salvador M, Vaz MA (2010) Low level laser therapy before eccentric exercise reduces muscle damage markers in humans. Eur J Appl Physiol 110(4):789-796. doi:10.1007/s00421-010-1562-Z

39. Marin DP, Bolin AP, Campoio TR, Guerra BA, Otton R (2013) Oxidative stress and antioxidant status response of handball athletes: implications for sport training monitoring. Int Immunopharmacol 17(2):462-470. doi:10.1016/j.intimp.2013.07. 009

40. Zembron-Lacny A, Slowinska-Lisowska M, Ziemba A (2010) Integration of the thiol redox status with cytokine response to physical training in professional basketball players. Physiol Res 59(2):239-245

41. Borghi SM, Zarpelon AC, Pinho-Ribeiro FA, Cardoso RD, Martins-Pinge MC, Tatakihara RI, Cunha TM, Ferreira SH, Cunha FQ, Casagrande R, Verri WA Jr (2014) Role of TNF-alpha/TNFR1 in intense acute swimming-induced delayed onset muscle soreness in mice. Physiol Behav 128:277-287. doi:10. 1016/j.physbeh.2014.01.023

42. Marklund P, Mattsson CM, Wahlin-Larsson B, Ponsot E, Lindvall B, Lindvall L, Ekblom B, Kadi F (2013) Extensive inflammatory cell infiltration in human skeletal muscle in response to an ultraendurance exercise bout in experienced athletes. J Appl Physiol (1985) 114(1):66-72. doi:10.1152/japplphysiol.01538. 2011

43. Cyktor JC, Turner J (2011) Interleukin-10 and immunity against prokaryotic and eukaryotic intracellular pathogens. Infect Immun 79(8):2964-2973. doi:10.1128/IAI.00047-11

44. Camargo MZ, Siqueira CP, Preti MC, Nakamura FY, de Lima FM, Dias IF, Toginho Filho Dde O, Ramos Sde P (2012) Effects of light emitting diode (LED) therapy and cold water immersion therapy on exercise-induced muscle damage in rats. Lasers Med Sci 27(5): 1051-1058. doi:10.1007/s10103-011-1039-2

45. Hayworth CR, Rojas JC, Padilla E, Holmes GM, Sheridan EC, Gonzalez-Lima F (2010) In vivo low-level light therapy increases cytochrome oxidase in skeletal muscle. Photochem Photobiol 86(3):673-680. doi:10.1111/j.1751-1097.2010.00732.x

46. Leal ECP, Lopes-Martins RAB, Baroni BM, De Marchi T, Rossi RP, Grosselli D, Generosi RA, de Godoi V, Basso M, Mancalossi JL, Bjordal JM (2009) Comparison between single-diode low-level laser therapy (LLLT) and LED multi-diode (Cluster) therapy (LEDT) applications before high-intensity exercise. Photomed Laser Surg 27(4):617-623. doi:10.1089/pho.2008.2350 